\title{
Effects of Tilletia foetida on Microbial Communities in the Rhizosphere Soil of Wheat Seeds Coated with Different Concentrations of Jianzhuang
}

\author{
Ghulam Muhae Ud Din ${ }^{1} \cdot{\text { Zhenzhen } \mathrm{Du}^{1} \cdot \text { Han Zhang }}^{1,2} \cdot$ Sifeng Zhao ${ }^{2} \cdot$ Taiguo Liu $^{1} \cdot$ Wanquan Chen ${ }^{1} \cdot$ Li Gao $^{1}$
}

Received: 12 October 2020 / Accepted: 17 January 2021 / Published online: 1 February 2021

(C) The Author(s) 2021

\begin{abstract}
Tilletia foetida (syn. T. laevis) leads to wheat common bunt, a worldwide disease that can lead to $80 \%$ yield loss and even total loss of production, together with degrading the quality of grains and flour by producing a rotten fish smell. To explore the potential microbial community that may contribute to the control of soil- and seed-borne pathogens, in this study, we analyzed the effects of the plant pathogenic fungus T. foetida on rhizosphere soil microorganisms in wheat seeds coated with different concentrations of a fungicide (Jianzhuang) used to control the disease. To analyze the bacterial and fungal abundance in T. foetida-infected and mock-infected plants, the microorganisms were sequenced using high-throughput HiSeq 2500 gene sequencing. The results showed that bacterial communities, including Verrucomicrobia, Patescibacteria, Armatimonadetes, Nitrospirae, Fibrobacteres, Chlamydiae, and Hydrogenedentes, and fungal communities, including Basidiomycota and Ciliophora, were more prevalent in the mock group than in the $T$. foetida-infected group, which may contribute to the control of wheat common bunt. Moreover, cluster and PCoA analysis revealed that replicates of the same samples were clustered together, and these results were also found in the distance index within-group analysis for bacterial and fungal communities in the $T$. foetida-infected and mock groups.
\end{abstract}

Keywords Wheat common bunt $\cdot$ Tilletia foetida $\cdot$ Fungi community $\cdot$ Bacterial community

\section{Introduction}

Tilletia foetida (syn. T. laevis) is a pathogen that can lead to wheat common bunt $[1,2]$. Plants infected with $T$. foetida usually produce a lower yield, with low quality compared to healthy plants. Reductions in the quality and quantity of infected plants occur due to replacement of mature grains with bunt sori [1]. Additionally, wheat flour millers usually refuse grains infected by $T$. foetida, as very low infection rates can

Ghulam Muhae Ud Din, Zhenzhen Du and Han Zhang contributed equally to this work.

\section{Li Gao}

xiaogaosx@hotmail.com

1 State Key Laboratory for Biology of Plant Disease and Insect Pests, Institute of Plant Protection, Chinese Academy of Agricultural Sciences, Beijing 100193, China

2 Key Laboratory at Universities of Xinjiang Uygur Autonomous Region for Oasis Agricultural Pest Management and Plant Protection Resource Utilization, Shihezi University, Xinjiang 832003, China result in obvious unwanted odors in flour [3, 4]. The disease incidence can reach 70 to $80 \%$ using T. foetida-susceptible seeds, with $41 \%$ yield loss in Romania [5] and losses reaching 25-30\% and 10-20\% in Iran and Turkey, respectively [6].

Rhizosphere soil is a dynamic and complex environment; its biological activity is typically regulated by microorganisms, which play crucial roles in sustaining the health of agricultural and natural soil systems [7]. It is well known that fungal and bacterial communities are responsible for multifaceted biological functions in soils, and maintaining the biodiversity of microbes is crucial to soil fitness [8]. However, many factors affect rhizosphere soil microorganisms, such as plant pathogens, which are a critical component of rhizosphere microbial communities and play an important role in plant growth and health [9]. Some fungi are known for biocontrol activity against pathogenic microorganisms [10], which positively support plant productivity by enhancing plant growth. However, some fungi negatively influence plant health, such as some plant pathogens in the soil; for example, Fusarium graminearum can cause stalk rot disease of maize [11], Verticillium nonalfalfae can cause verticillium wilt on tree of heaven [12], and Macrophomina 
phaseolina can cause dry root rot disease [13]. T. foetida is a soil- and seed-borne pathogen that leads to wheat common bunt, which may cause $80 \%$ loss in China and degrade the quality of wheat seeds and flour by producing rotten fish smells. Moreover, the teliospores of the pathogen can live in soil for up to 10 years and can germinate or even undergo excretion by animals or people.

Seed treatments with fungicides are broadly used to control some fungal pathogens, such as Alternaria alternata and Fusarium sp. $[14,15]$. T. foetida has the ability to penetrate locally into host plants, and seed treatment with fungicides is approved as an option for its control [16]. Common bunt symptoms appear during the boot stage under conducive environmental conditions and are difficult to control at this stage through fungicide spraying [17]. Therefore, fungicide application for seed treatment has been used for disease control. Previous studies showed that Jianzhuang fungicide has good results against different pathogens, such as Pseudomonas, compared to triazole, a common wheat fungicide, against different fungal pathogens [18-20]. However, pesticides often affect microorganisms in the soil based on the dose, properties of the soil, and environmental factors [21-23]. Some studies have shown that glyphosate application increased Proteobacteria concentrations in the rhizospheres of corn (Zea mays) and soybean (Glycine max) [24]. Ryan concluded that pesticide usage might affect some groups of microorganisms in the soil but has little effect on the soil community [25]. Gupta and Kalia [23] reported that the usage of pesticides affects all of the soil microbes, with reductions in the average populations of all groups studied in soil samples from fields with rice-wheat cropping. Regarding the use of Jianzhuang in controlling wheat common bunt, there is little information on the effects of fungicides on soil microorganisms.

To optimize the concentration of Jianzhuang applied on wheat seeds, based on Illumina HiSeq 2500 sequencing, this study characterized the rhizosphere fungal and bacterial communities in the context of infection with the plant pathogen T. foetida. Our work will lay a foundation for potential biocontrol activity with rhizosphere bacterial and fungal communities and provide insights into the interactions of plant pathogens, rhizosphere bacteria and fungi, and plant growth.

\section{Materials and Methods}

\section{Plant Material and Pesticide Application}

The wheat (Triticum aestivum L.) spring cultivar Morocco (highly susceptible) was obtained from the Institute of Plant Protection (IPP), Chinese Academy of Agricultural Sciences (CAAS), Beijing, China. Wheat seeds were sterilized with $30 \%$ sodium hypochlorite for $5 \mathrm{~min}$, rinsed 5 times in $\mathrm{ddH}_{2} \mathrm{O}$, and germinated for 30 days in an incubator
(AUCMA, Qing Dao, China) to vernalize after fungicide application. The fungicide programs are illustrated in Table 1. After vernalization, seedlings were grown in a 1:2 mixture of organic matter (peat moss, Beijing, China) and soil (Beijing, China) in pots. Seedlings were grown in a 14-h light/10-h dark cycle at $15{ }^{\circ} \mathrm{C}$ to the tillering stage and at $25^{\circ} \mathrm{C}$ at the boot stage.

\section{Fungal Inoculation}

T. foetida was grown on $2 \%$ agar media and incubated for 15 days at $15^{\circ} \mathrm{C}$ under $24 \mathrm{~h}$ of light. The mycelium of T. foetida was harvested under laminar flow by adding $5 \mathrm{~mL}$ of $\mathrm{ddH}_{2} \mathrm{O}$ onto each $T$. foetida culture plate. Hyphae of T. foetida were injected 5 times into the root zone at 2-day intervals, while mock plants were treated with $\mathrm{ddH}_{2} \mathrm{O}$. The suspension contained infectious hyphae at a concentration of $10^{6} \mathrm{cfu} / \mathrm{mL}$ with an $\mathrm{OD}_{600}$ of 0.15 . Rhizosphere soil was collected during the booting stage of wheat from $T$. foetidainfected and mock plants.

\section{Molecular Detection of the Infection of $T$. foetida in Inoculated Wheat Leaves}

DNA was extracted from wheat leaves 1 week after $T$. foetida inoculation using a Plant Genomic DNA Kit (TianGen, China). The primer sequences for $T$. foetida were (5'-TCAC TTCAAGGTCGTTCCCG-3')/L60R (5'-CGGG TCGAGGGGCGTAAACTTGA-3'). Polymerase chain reaction (PCR) and gel electrophoresis were performed to visualize the expected 660-bp band of $T$. foetida with high specificity, as described by Yao et al. [4].

\section{Soil Sampling}

Soil samples were collected from both $T$. foetida-infected and mock pots at $20 \mathrm{~cm}$ depth. For each sample, there were 6 T. foetida-infected plants and 6 mock plants, with 6

Table 1 Jianzhuang application against $T$. foetida infected and mock in wheat rhizosphere

\begin{tabular}{llll}
\hline Treatments & Treatments (\%) & Infected & Mock \\
\hline $2.25 \mathrm{~mL} / 100 \mathrm{~kg}$ & $1.5 \%$ of RD & IA & NG \\
$4.5 \mathrm{~mL} / 100 \mathrm{~kg}$ & $3 \%$ of RD & IB & NH \\
$7.5 \mathrm{~mL} / 100 \mathrm{~kg}$ & $5 \%$ of RD & IC & NI \\
$150 \mathrm{~mL} / 100 \mathrm{~kg}$ & $\mathrm{RD}$ & ID & $\mathrm{NJ}$ \\
$225 \mathrm{~mL} / 100 \mathrm{~kg}$ & 1.5 time of RD & IE & NK \\
No seed treatment & - & IF & NL \\
\hline
\end{tabular}

RD stand for recommend dose of Jianzhuang for wheat. Infected means inoculation of $T$. foetida in the root zone of the plants, while mock means no application of $T$. foetida 
rhizosphere soil samples collected from each infected plant and 6 from mock plants. After shaking the roots to remove loose soil, a sterile brush was used to collect the residual soil from the roots. Equal amounts of rhizosphere soil from the three wheat plants were mixed and stored at $-80{ }^{\circ} \mathrm{C}$. Ten grams of rhizosphere soil was collected and mixed into $90 \mathrm{~mL}$ of distilled water in a $150-\mathrm{mL}$ tube (Houdior, China). These tubes were shaken for $10 \mathrm{~min}$ in an incubator shaker (ZHWY-200D, China) and incubated for $5 \mathrm{~min}$. Soil solution $(1 \mathrm{~mL})$ for every sample was taken and sequenced after culturing.

\section{DNA Extraction and PCR Amplification}

Soil microbial DNA was extracted using a HiPure soil DNA kit (Magen, Guangzhou, China) following the manufacturer's protocols. DNA was extracted from $0.5 \mathrm{~g}$ of soil suspension. The concentration and quality of every extracted DNA sample were evaluated based on the $260 / 280 \mathrm{~nm}$ and $260 / 230 \mathrm{~nm}$ absorbance ratios obtained using a NanoDrop 2000 (Thermo Scientific, USA). With the primers $341 \mathrm{~F}$ (5'-CCTA GGGNGGCWGCAG-3') and 806R (5'-GGAC TACHVGGGTATCTAAT-3') for V3-V4 of the 16S RNA gene and ITS3_KYO2 (5'-GATGAAGAACGYAGYRAA$\left.3^{\prime}\right)$ and ITS4 (5'-TCCTCCGCTTATTGATATGC-3') for ITS2 region of ribosomal DNA, PCRs were performed in triplicate with a total volume of $50 \mu \mathrm{L}$, including $5 \mu \mathrm{L}$ of $10 \times$ KOD buffer, $5 \mu \mathrm{L}$ of $2.5 \mathrm{mM}$ dNTPs, $1.5 \mu \mathrm{L}$ of each primer $(5 \mu \mathrm{M}), 1 \mu \mathrm{L}$ of KOD polymerase, and $100 \mathrm{ng}$ of template DNA. The amplification program was $95^{\circ} \mathrm{C}$ for $2 \mathrm{~min}$, followed by 27 cycles at $98^{\circ} \mathrm{C}$ for $10 \mathrm{~s}, 62^{\circ} \mathrm{C}$ for $30 \mathrm{~s}$, and a final extension of $68^{\circ} \mathrm{C}$ for $10 \mathrm{~min}$.

\section{Illumina HiSeq 2500 Sequencing}

PCR products were recovered using a 1.5\% agarose gel and purified using an AxyPrep DNA Gel Extraction Kit (Axygen Biosciences, Union City, CA, USA) according to the manufacturer's guidelines and quantified using an ABI Step OnePlus Real-time PCR system (Life Technologies, Foster City, USA). Purified amplicons were pooled in equimolar amounts and paired-end sequenced $(2 \times 250)$ on an Illumina platform according to standard protocols. Raw readings were stored in the NCBI Sequence Read Archive (SRA) database. Sequencing was performed in triplicate using samples from three independent experiments.

\section{Data Analysis}

After sequencing, all raw reads were analyzed using the QIIME standard pipeline [26] to trim the low-quality reads. Operational taxonomic units (OTUs) were clustered with a 97\% similarity cutoff using UPARSE [27] (version 7.1 http://drive5.com/uparse/). The taxonomic classification was further checked using the Ribosomal Database Project (RDP) classifier (version 2.2) based on the Greengenes Database with 0.8 to 1 confidence $[28,29]$. With the cluster file, alpha diversity statistics, including the Chao1 richness estimate, Shannon diversity index, and Simpson diversity index were calculated in MOTHUR for each sample [30, 31]. Beta diversity statistics based on UniFrac metrics were also carried out, including cluster analysis, weighted UniFrac distance metrics, and principal component analysis (PCoA) [31, 32]. Cluster analysis (CA) was used to group communities of twelve different samples. Weighted UniFrac distance metrics were used to estimate the community diversity of twelve samples. PCoA analysis to compare the discrepancies among individuals and communities was conducted based on (1) taxonomy results from the NCBI database; (2) OTUs described above; and (3) weighted UniFrac metrics.

\section{Results}

\section{Phylotypes and Diversity of the Microbial Community}

The soil samples were obtained from infected and mock plants with different concentrations of Jianzhuang, which were verified by specific primer markers of $T$. foetida (Figure S1). Using Illumina HiSeq 2500 sequencing, raw reads were produced for these samples. After filtering the raw reads using the QIME standard pipeline and removing all other chimeric tags, effective tags were used for further analysis. Average, total, minimum, and maximum ratios of all samples for raw data, clean data, raw tags, clean tags, and effective tags were calculated with the effective ratio. In total, 83,483-106,580 effective tags were obtained for these samples. Additionally, the percentage of valid data for each sample was more than $88 \%$, indicating that at least $88 \%$ of tags of each sample met the requirements of sequencing length and quality (Table S1).

Furthermore, the number of OTUs was calculated for bacterial communities with three replications for each sample, and the changes in species abundance were also calculated from the domain to species level. OTU results showed that there were different species present during sequencing. The expression abundance levels of 10 species reached at least $2 \%$ in one sample, while other species were classified into unclassified categories (Table S2). Similarly, OTUs were calculated for the fungal species with three replications for every sample; the list of these species is provided in Table S3.

\section{Bacterial Communities in Rhizosphere Soil After $T$. foetida Inoculation}

There were differences in the OTUs within T. foetida-infected and mock libraries of Jianzhuang-coated seeds. The relative 


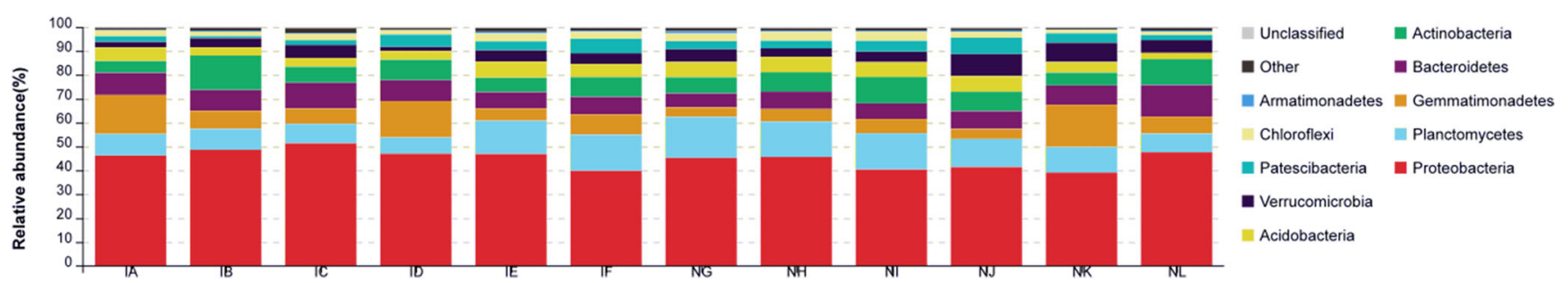

Fig. 1 Bacterial compositions of the different communities in rhizosphere soil. Relative abundance levels of different bacterial phyla within different libraries. IA ( $T$. foetida $+1.5 \%$ RD of Jianzhuang), IB (T. foetida $+3 \%$ RD of Jianzhuang), IC ( $T$. foetida $+5 \%$ RD of Jianzhuang), ID (T. foetida + RD of Jianzhuang), IE (T. foetida +1.5

abundance of different microbial communities varied in the T. foetida-infected and mock samples. The results showed that the IC (5\% RD) library had maximum abundance, while the IF (no seed treatment) and NK (mock of 1.5 times RD) libraries had minimum relative abundance of Proteobacteria. However, the overall abundance of Proteobacteria was high in T. foetida-infected libraries. Similarly, the relative abundance of Planctomycetes was high in the mock group, including the NG (1.5\% RD), NH (3\% RD), NI (5\% RD), and NJ (RD) groups, compared to the $T$. foetida-infected group, including the IA ( $1.5 \% \mathrm{RD}), \mathrm{IB}(3 \% \mathrm{RD}), \mathrm{IC}(5 \% \mathrm{RD})$, and ID (RD) samples. Additionally, the abundance levels of all other bacterial phyla were different under different treatments (Fig. 1).

\section{Fungal Communities in Rhizosphere Soil After T. foetida Infection}

Fungal communities were analyzed after $T$. foetida infection in Jianzhuang-coated seeds using OTU analysis (Table S3). The $T$. foetida-infected samples from the IB (3\% RD) library had the maximum number of Ascomycota. The relative abundance of Basidiomycota was higher in the mock-infected libraries than in the T. foetida-infected libraries. The maximum abundance of Basidiomycota was found in the NH (mock of $3 \%$ RD) library, and the minimum abundance of Basidiomycota was found in the infected IE (1.5\% RD) library, suggesting that Jianzhuang (1.5\% RD) was better for controlling $T$. foetida infection. Additionally, the abundance times RD of Jianzhuang), IF (T. foetida + no Jianzhuang), NG (mock + $1.5 \%$ RD of Jianzhuang), NH (mock $+3 \%$ RD of Jianzhuang), NI (mock $+5 \%$ RD of Jianzhuang), NJ (mock $+\%$ RD of Jianzhuang), NK (mock + 1.5 times RD of Jianzhuang), and NL (mock + no Jianzhuang). RD stands for recommended dose, and mock means $\mathrm{ddH}_{2} \mathrm{O}$ application

levels of all other fungal phyla were different under different treatments (Fig. 2).

\section{Cluster and Principal Component Analysis for Bacterial Communities}

As shown in Fig. 3a, comparing the distances between the six treatments and their control, it can be seen for the two groups, 5\% "Jianzhuang" dressing (IC) and its control (NI) and 1 times "Jianzhuang" dressing (ID) and its control (NJ), the treatment group is the farthest from the control group. This was followed by $1.5 \%$ "Jianzhuang" seed dressing (IA) and its control (NG) and 1.5 times "Jianzhuang" seed dressing (IE) and its control (NK). Among the two groups of 3\% "Jianzhuang" seed dressing (IB) treatment and its control (NH), and no seed treatment (IF) and its control (NL), the distance between the treatment and the control is relatively small.

Based on the unweighted UniFrac distance metrics, PCoA was performed to assess the similarities of different infected and mock libraries in Jianzhuang-coated seeds. The PCoA analysis results revealed maximum variations of $56.93 \%$ (PC1) and $11.96 \%$ (PC2), as shown in Fig. 3b. Similar results were also obtained between the 3\% "Jianzhuang" seed dressing (IB) treatment and the control (NH), the no seed treatment group (IF) and the control (NL). The distance between these two groups was small, and the distance between the other groups was large. We also found that among all of the inoculated treatment groups, IA (1.5\% RD), IC (5\% RD), and ID

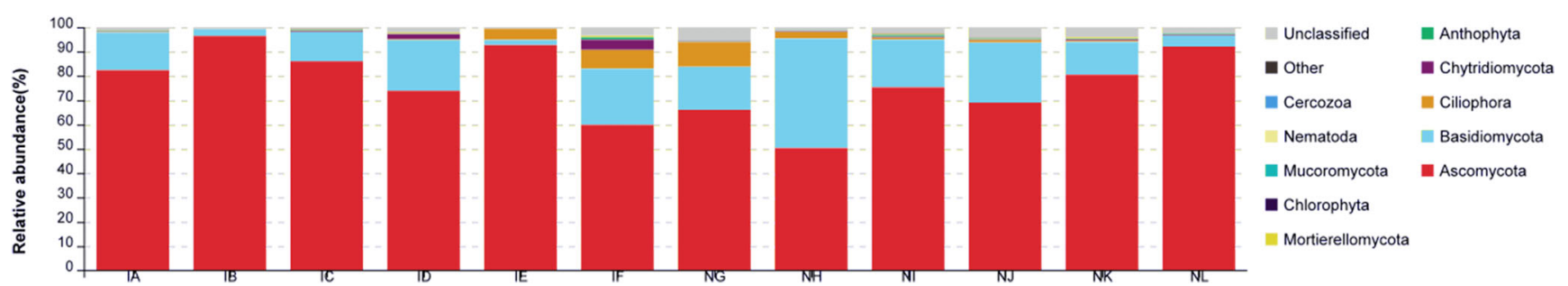

Fig. 2 Fungal compositions of the different communities in rhizosphere soil. Relative abundance levels of different fungal phyla within different samples. IA ( $T$. foetida $+1.5 \%$ RD of Jianzhuang), IB ( T. foetida $+3 \%$ $\mathrm{RD}$ of Jianzhuang), IC ( $T$. foetida $+5 \%$ RD of Jianzhuang), ID ( $T$. foetida $+\mathrm{RD}$ of Jianzhuang), IE ( $T$. foetida +1.5 times RD of Jianzhuang), IF

(T. foetida + no Jianzhuang), NG (mock $+1.5 \%$ RD of Jianzhuang), $\mathrm{NH}$ (mock $+3 \%$ RD of Jianzhuang), NI (mock $+5 \%$ RD of Jianzhuang), NJ (mock $+\%$ RD of Jianzhuang), NK (mock +1.5 times RD of Jianzhuang), and NL (mock + no Jianzhuang). RD stands for recommended dose, and mock means $\mathrm{ddH}_{2} \mathrm{O}$ application 

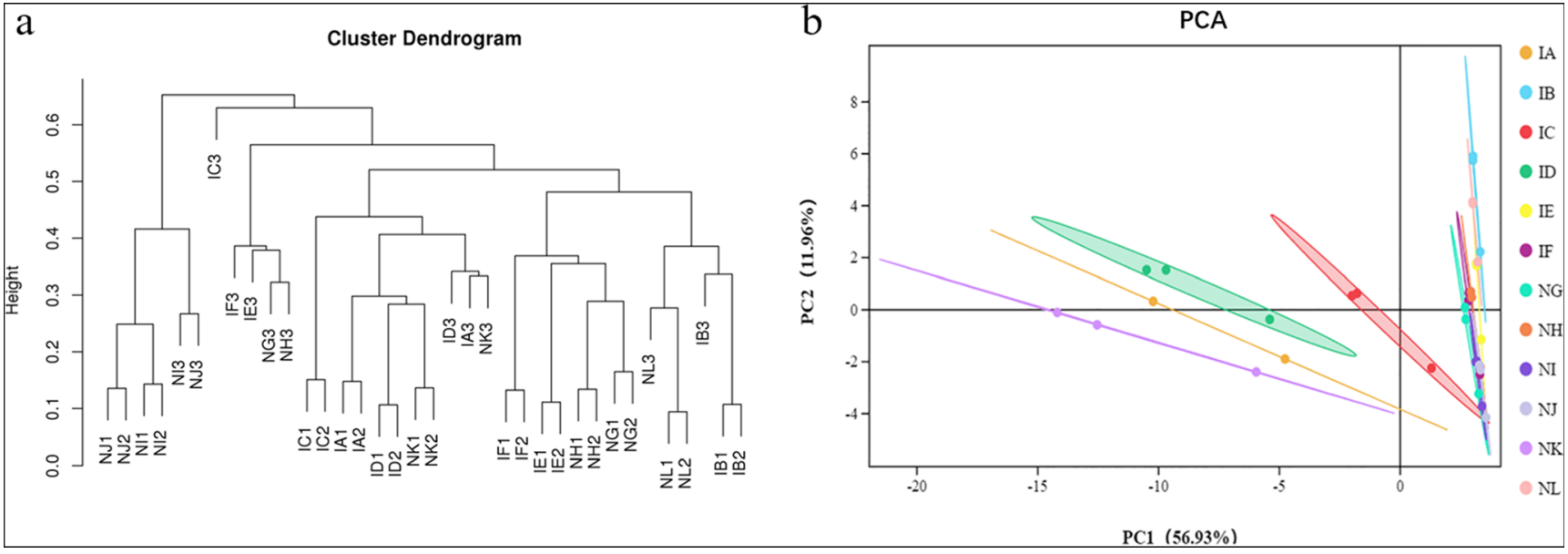

Fig. 3 Beta $(\beta)$ diversity of twelve bacterial samples. a Phylogenetic tree. b Two-dimensional PCoA analysis. IA ( $T$. foetida $+1.5 \% \mathrm{RD}$ of Jianzhuang), IB ( $T$. foetida $+3 \%$ RD of Jianzhuang), IC (T. foetida + $5 \%$ RD of Jianzhuang), ID ( $T$. foetida + RD of Jianzhuang), IE ( $T$. foetida +1.5 times RD of Jianzhuang), IF ( $T$. foetida + no Jianzhuang), NG

(mock $+1.5 \%$ RD of Jianzhuang), $\mathrm{NH}$ (mock $+3 \%$ RD of Jianzhuang), NI (mock $+5 \%$ RD of Jianzhuang), NJ (mock + \% RD of Jianzhuang), NK (mock + 1.5 times RD of Jianzhuang), and NL (mock + no Jianzhuang). RD stands for recommended dose, and mock means $\mathrm{ddH}_{2} \mathrm{O}$ application

(RD) were farther away from the other treatments, while the distances between IB (3\% RD) and IE (1.5 times RD) were closer, indicating that the effects of these two concentrations of Jianzhuang seed dressings on the rhizosphere bacterial community were similar.

\section{Cluster and Principal Component Analysis of Fungal Communities}

In Fig. 4a, comparing the distances between the 6 treatments and their mock, the distance between the $3 \%$ "Jianzhuang" seed dressing (IB) treatment and the mock $(\mathrm{NH})$ treatment was the largest. Among the three groups of 5\% "Jianzhuang" seed dressing (IC) and its mock (NI), 1 time of "Jianzhuang" seed

a

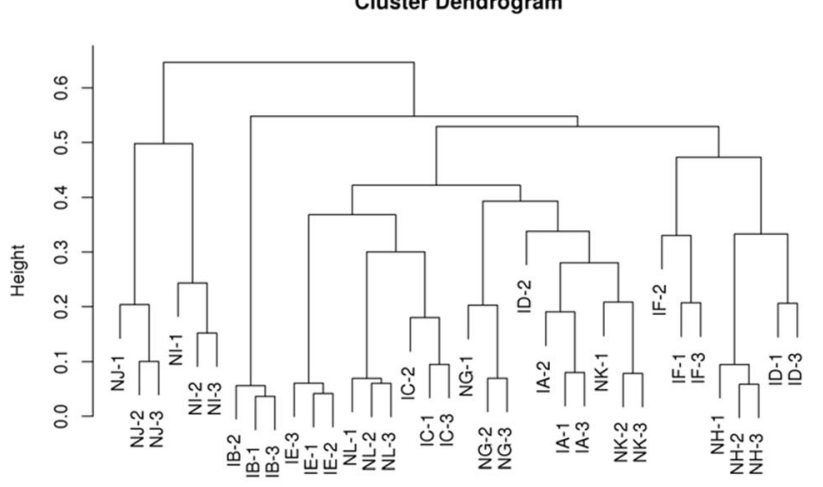

Fig. 4 Beta ( $\beta$ ) diversity of twelve fungal samples. a Phylogenetic tree. b Two-dimensional PCoA analysis. IA ( $T$. foetida $+1.5 \% \mathrm{RD}$ of Jianzhuang), IB (T. foetida $+3 \%$ RD of Jianzhuang), IC (T. foetida + $5 \%$ RD of Jianzhuang), ID ( $T$. foetida + RD of Jianzhuang), IE ( $T$. foetida +1.5 times RD of Jianzhuang), IF ( $T$. foetida + no Jianzhuang), NG dressing (ID) and its mock (NJ), and no seed treatment (IF) and its mock (NL), the distance between the treatments and their mock was slightly shorter. Among $1.5 \%$ "Jianzhuang" seed dressing (IA) and its mock (NG) and 1.5 times "Jianzhuang" seed dressing (IE) and its mock (NK), the difference between the treatment group and the control group was relatively small.

The results of $\mathrm{PCoA}$ revealed maximum variations of $59.34 \%$ (PC1) and 20.13\% (PC2). It can be seen from Fig. $4 \mathrm{~b}$ that both the treatment group and the mock group have good repeatability, and the sample is in a confidence circle. At the same time, the distance between each group and their mock was large, indicating that $T$. foetida has a relatively large impact on the fungal community of wheat rhizosphere soil.

b

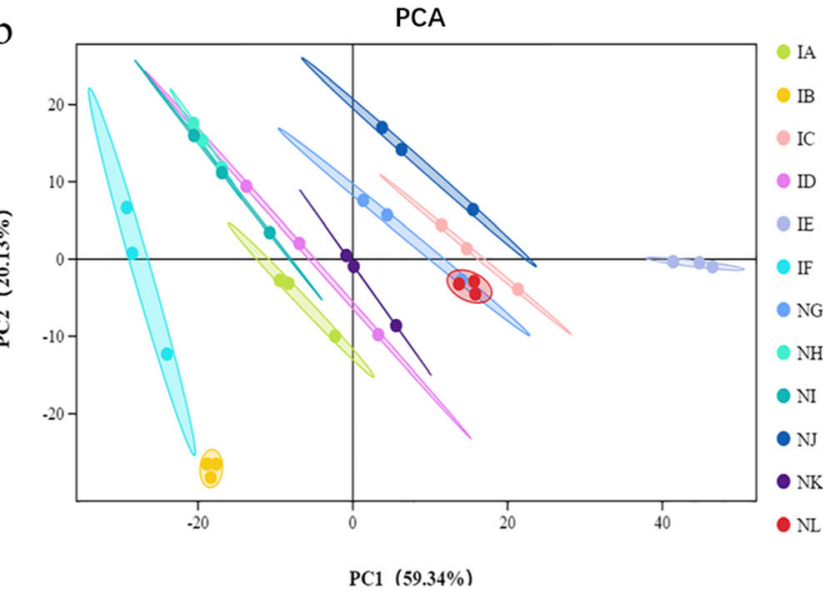

(mock $+1.5 \%$ RD of Jianzhuang), $\mathrm{NH}$ (mock $+3 \%$ RD of Jianzhuang), NI (mock $+5 \%$ RD of Jianzhuang), NJ (mock + \% RD of Jianzhuang), NK (mock +1.5 times RD of Jianzhuang), and NL (mock + no Jianzhuang). RD stands for recommended dose, and mock means $\mathrm{ddH}_{2} \mathrm{O}$ application 


\section{Heatmap Analysis for Bacterial Communities}

The abundance levels of eighteen bacterial phyla were characterized in T. foetida-inoculated and mock libraries. Community heatmap analysis was scaled to demonstrate the abundance levels of the various bacterial communities. The results showed that Proteobacteria (IC, T. foetida infected + $5 \% \mathrm{RD})$, Actinobacteria (IB, T. foetida infected $+3 \% \mathrm{RD}$ ), Firmicutes (IC, T. foetida infected $+5 \%$ RD), BRC1 (IB, T. foetida infected $+3 \% \mathrm{RD}$ ), Cyanobacteria (IC, T. foetida infected $+5 \%$ RD), and Elusimicrobia (IE, T. foetida infected +1.5 times of RD) were abundant in the $T$. foetida infected compared to mock samples, while Planctomycetes (NG, mock $+1.5 \% \mathrm{RD}$ ), Bacteroidetes (NL, mock + no Jianzhuang treatment), Verrucomicrobia (NJ, mock + RD), Patescibacteria (NJ, mock + RD), Chloroflexi (NI, mock $+5 \%$ RD), Armatimonadetes (NG, mock $+1.5 \% \mathrm{RD})$, Nitrospirae (NI, mock $+1.5 \%$ RD), Fibrobacteres (NI, mock $+1.5 \%$ RD), Chlamydiae (NI, mock $+1.5 \% \mathrm{RD}$ ), and Hydrogenedentes (NG, mock $+1.5 \% \mathrm{RD}$ ) were abundant in the mock compared to T. foetida-infected libraries. However, Gemmatimonadetes (NK (1.5 times of RD), ID (RD), and IA (1.5\% RD)) and Acidobacteria had similar abundances in T. foetida-infected and mock samples (Fig. 5).

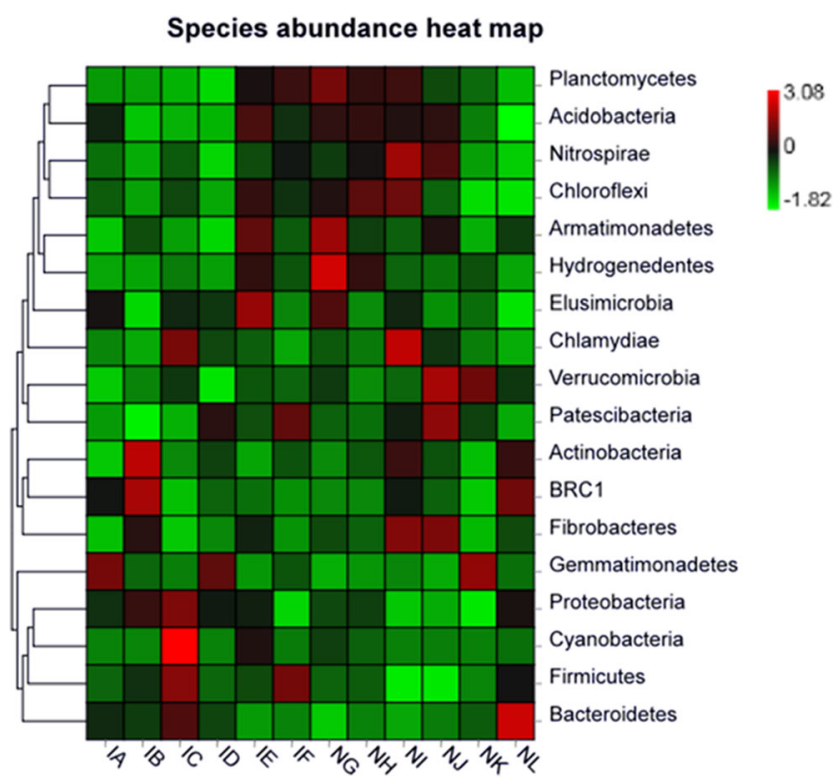

Fig. 5 Profiling results for the twelve samples. Richness heatmap of the 18 most abundant bacterial phyla. IA ( $T$. foetida $+1.5 \%$ RD of Jianzhuang), IB ( $T$. foetida $+3 \%$ RD of Jianzhuang), IC (T. foetida + $5 \%$ RD of Jianzhuang), ID ( $T$. foetida + RD of Jianzhuang), IE ( $T$. foetida +1.5 times RD of Jianzhuang), IF ( $T$. foetida + no Jianzhuang), NG (mock $+1.5 \%$ RD of Jianzhuang), $\mathrm{NH}$ (mock $+3 \%$ RD of Jianzhuang), NI (mock $+5 \%$ RD of Jianzhuang), NJ (mock + RD of Jianzhuang), NK (mock +1.5 times RD of Jianzhuang), and NL (mock + no Jianzhuang). RD stands for recommended dose, and mock means $\mathrm{ddH}_{2} \mathrm{O}$ application

\section{Heatmap Analysis for Fungal Communities}

The abundance levels of seven fungal phyla were characterized into $T$. foetida-infected and mock libraries. The results revealed that only Ascomycota $(\mathrm{IB}=3 \% \mathrm{RD})$ was abundant in the $T$. foetida-infected libraries, while Basidiomycota $(\mathrm{NH}=3$ $\mathrm{RD})$, Ciliophora (NG, mock $+1.5 \% \mathrm{RD})$, Chytridiomycota (IF, T. foetida infected with no Jianzhuang treatment), Anthophyta (IF, T. foetida infected with no Jianzhuang treatment), and Chlorophyta (NI, mock $+5 \%$ RD) were more abundant in mock libraries than in T. foetida-infected libraries. However, Mortierellomycota had similar abundance in T. foetida-infected (ID, $T$. foetida $+\mathrm{RD}$ ) and mock (NK, mock +1.5 times RD) libraries (Fig. 6).

\section{Alpha Diversity Analysis of Bacterial and Fungal Communities in Wheat Rhizosphere Soil}

PCoA analysis provided little variability information, and distance index within-group analysis was further used to assess the distance within groups. The results showed that the IB (3\% RD), NI (mock of 5\% RD), ID (RD), NJ (mock of RD), and NL (mock of no Jianzhuang treatment) libraries had lower distances within the groups (Fig. 7).

Alpha $(\alpha)$ diversity analysis was also performed for fungal communities. The results showed that the IB (3\% RD), NH (mock of 3\% RD), IE (1.5 times RD), and NL (mock of no Jianzhuang treatment) libraries had minimum distances within the groups compared to the other samples (Fig. 8).

\section{Discussion}

In this study, we investigated the effects of $T$. foetida on the microbial community with different concentrations of Jianzhuang pesticide-coated seeds and identified some

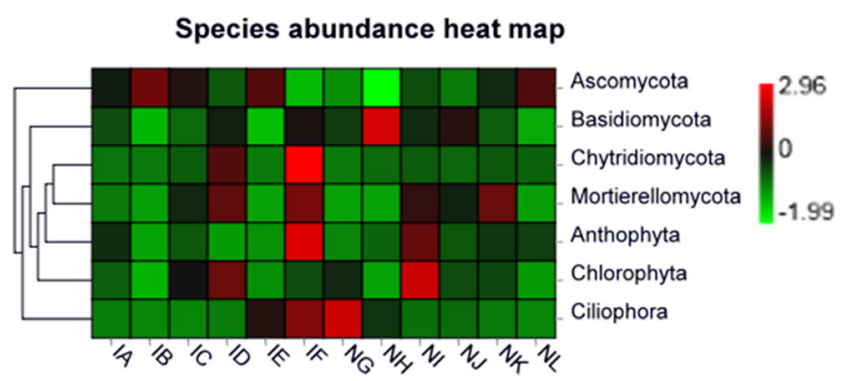

Fig. 6 Profiling results of the twelve samples. Richness heatmap of the 7 most abundant fungal phyla. IA ( $T$. foetida $+1.5 \% \mathrm{RD}$ of Jianzhuang), IB (T. foetida $+3 \%$ RD of Jianzhuang), IC ( $T$. foetida $+5 \%$ RD of Jianzhuang), ID ( $T$. foetida $+\mathrm{RD}$ of Jianzhuang), IE ( $T$. foetida +1.5 times RD of Jianzhuang), IF ( $T$. foetida + no Jianzhuang), NG (mock + $1.5 \%$ RD of Jianzhuang), NH (mock $+3 \%$ RD of Jianzhuang), NI (mock $+5 \%$ RD of Jianzhuang), NJ (mock +\% RD of Jianzhuang), NK (mock + 1.5 times RD of Jianzhuang), and NL (mock + no Jianzhuang). RD stands for recommended dose, and mock means $\mathrm{ddH}_{2} \mathrm{O}$ application 


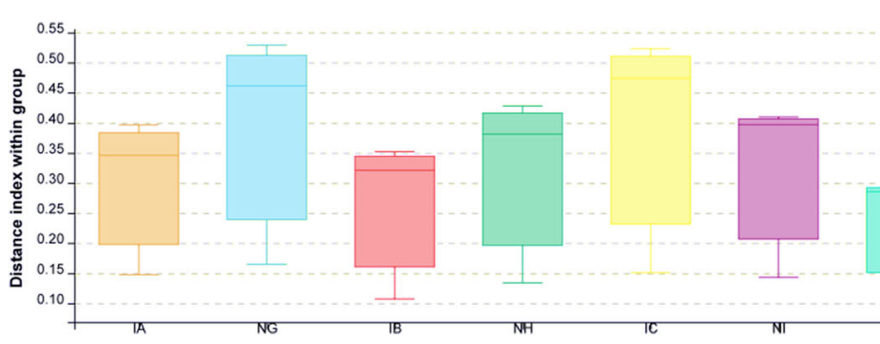

Fig. 7 Alpha $(\alpha)$ diversity levels of twelve bacterial samples. IA ( $T$. foetida $+1.5 \%$ RD of Jianzhuang), IB ( $T$. foetida $+3 \%$ RD of Jianzhuang), IC (T. foetida $+5 \%$ RD of Jianzhuang), ID ( $T$. foetida + $\mathrm{RD}$ of Jianzhuang), IE ( $T$. foetida +1.5 times RD of Jianzhuang), IF ( $T$. foetida + no Jianzhuang), NG (mock $+1.5 \%$ RD of Jianzhuang),

communities that may contribute to the control of wheat common bunt, which will provide some important information on the interaction of the rhizosphere community with plant growth.

The raw reads, clean reads, raw tags, clean tags, effective tags, and effective ratio (\%) were calculated for each treatment (Table S1) and were consistent with previous reports [33]. T. foetida-infected samples with Jianzhuang at different concentrations had slightly higher Proteobacteria and Gemmatimonadetes relative abundance levels than the mock libraries (Fig. 1). These findings suggest that Jianzhuang increased Proteobacteria diversity, which was affected by T. foetida. Previous studies revealed that Proteobacteria has roles in plant disease suppression and gene regulation, which have plant growth-promoting activities [34-36]. Interestingly, T. foetida belongs to the phylum Basidiomycota, and T. foetida-infected samples had a slightly lower abundance of Basidiomycota, possibly because of Jianzhuang application [37]. However, the relative abundance of the phylum Ascomycota was greater in the T. foetida-infected samples (Fig. 2) [38]. The observed results in this experiment revealed that $T$. foetida might increase the abundance levels of some fungal communities.

Based on the unweighted UniFrac distance metric, cluster and PCoA analyses were conducted to evaluate the similarities among the T. foetida-infected and mock libraries [39]. The results of cluster analysis (Fig. 3a) and PCoA analysis (Fig. 3b) showed that replicate samples of the same treatment under the same concentration of Jianzhuang were similar. Additionally, similar results were observed for the fungal phyla during cluster and PCoA analysis (Fig. 4a, b). The richness levels of eighteen bacterial phyla were checked in the T. foetida-infected and mock libraries. Actinobacteria and Cyanobacteria are able to suppress different plant pathogens and promote the morpho-physiological attributes of plants $[40,41]$. Our results revealed that the richness levels of Actinobacteria and Cyanobacteria were high in T. foetida-infected plants, suggesting that Jianzhuang activates Actinobacteria and Cyanobacteria richness. Additionally, Nitrospirae abundance was high in mock samples (Fig. 5). Previous results reported that Oehmen played an important role in nitrogen fixation and removal [42]. In our results, Nitrospirae abundance was low, suggesting that $T$. foetida might have a negative impact on it. Similarly, the richness levels of seven fungal phyla were demonstrated in the T. foetida-infected and mock samples. The richness of Basidiomycota was abundant in the $\mathrm{NH}$ (3\% RD) sample. T. foetida belongs to the phylum Basidiomycota, which suggests that Jianzhuang inhibits the proliferation of $T$. foetida (Fig. 6).

Advances in the knowledge of rhizosphere soil microbial diversity depend on improved approaches [43]. Soil microorganisms play important roles in soil fertility and soil

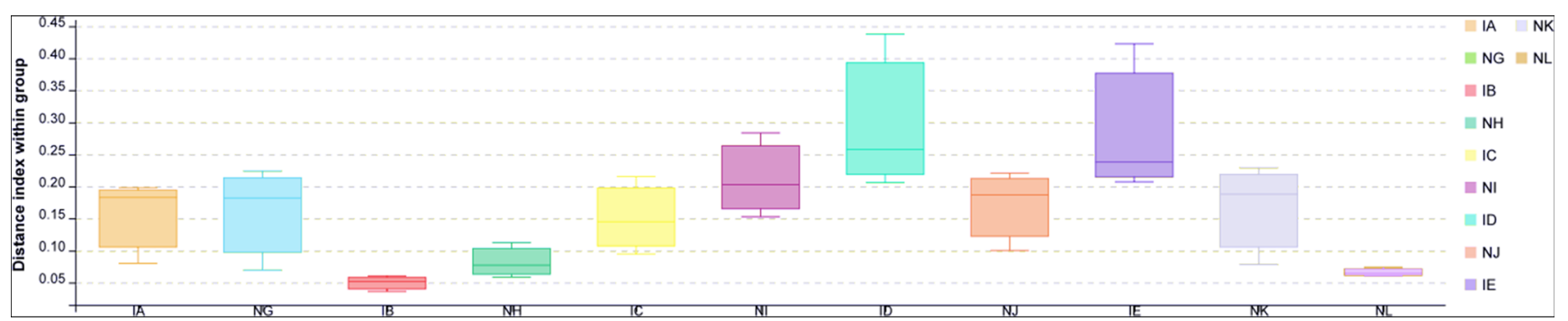

Fig. 8 Alpha $(\alpha)$ diversity levels of twelve fungal samples. IA (T. foetida $+1.5 \%$ RD of Jianzhuang), IB (T. foetida $+3 \%$ RD of Jianzhuang), IC (T. foetida $+5 \%$ RD of Jianzhuang), ID ( $T$. foetida + RD of Jianzhuang), IE ( $T$. foetida +1.5 times RD of Jianzhuang), IF ( $T$. foetida + no Jianzhuang), NG (+1.5\% RD of Jianzhuang), NH (mock $+3 \%$ RD of
Jianzhuang), NI (mock $+5 \%$ RD of Jianzhuang), NJ (mock $+\%$ RD of Jianzhuang), NK (mock + 1.5 times RD of Jianzhuang), and NL (mock + no Jianzhuang). RD stands for recommended dose, and mock means application of $\mathrm{ddH}_{2} \mathrm{O}$ instead of $T$. foetida 
biochemical processes and regulate soil temperature [44-48]. It is acknowledged that traditional molecular biological techniques such as simple PCR, terminal restriction fragmentlength polymorphism (T-RFLP), and denaturing gradient gel electrophoresis (DGGE) have their own forms of reference and have intense labor requirements [49]. Next-generation sequencing has been described as easier and more accurate than traditional molecular techniques in characterizing rhizosphere soil microorganisms under controlled and natural conditions. Plant morpho-physiological attributes and performance are highly associated with plant-associated soil microorganisms under different conditions [50]. Up to a few thousand different species of bacteria, fungi, and various protists, including plant roots, act as biocontrol agents against various plant pathogens [50-53].

Previous studies have found that microbial abundance was greater in infected samples than in mock samples [7, 54]. The results of this study suggested that inoculation with $T$. foetida had negative effects on the rhizosphere soil microbial community by increasing or decreasing their relative abundance levels. The abundance levels of the bacterial communities Verrucomicrobia, Patescibacteria, Armatimonadetes, Nitrospirae, Fibrobacteres, Chlamydiae, and Hydrogenedentes and the fungal communities Basidiomycota and Ciliophora were higher in the mock group than in the T. foetida-infected group, which may contribute to the control of wheat common bunt.

Supplementary Information The online version contains supplementary material available at https://doi.org/10.1007/s00248-021-01696-w.

Author Contribution Li Gao designed the experiment and wrote the manuscript; Han Zhang performed the experiment; Ghulam Muhae Ud Din and Zhenzhen Du revised and analyzed the manuscript; and Wanquan Chen, Taiguo Liu, and Sifeng Zhao provided the materials. All authors were involved in writing the paper and had final approval to publish the manuscript.

Funding This work was supported by the National Natural Science Foundation of China (31761143011) and the National Key Research and Development Program of China (2018YFD0200406).

\section{Declarations}

Conflict of Interest The authors declare no competing interests.

Open Access This article is licensed under a Creative Commons Attribution 4.0 International License, which permits use, sharing, adaptation, distribution and reproduction in any medium or format, as long as you give appropriate credit to the original author(s) and the source, provide a link to the Creative Commons licence, and indicate if changes were made. The images or other third party material in this article are included in the article's Creative Commons licence, unless indicated otherwise in a credit line to the material. If material is not included in the article's Creative Commons licence and your intended use is not permitted by statutory regulation or exceeds the permitted use, you will need to obtain permission directly from the copyright holder. To view a copy of this licence, visit http://creativecommons.org/licenses/by/4.0/.

\section{References}

1. Mourad A, Mahdy E, Bakheit BR et al (2018) Effect of common bunt infection on agronomic traits in wheat (Triticum aestivum $\mathrm{L}$.). J Plant Genet Breed 2:1-7

2. El-Naimi M, Toubia-Rahme H, Mamluk OF (2000) Organic seedtreatment as a substitute for chemical seed-treatment to control common bunt of wheat. Eur J Plant Pathol 106:433-437

3. Lu ZX, Gaudet DA, Frick M, Puchalski B, Genswein B, Laroche A (2005) Identification and characterization of genes differentially expressed in the resistance reaction in wheat infected with Tilletia tritici, the common bunt pathogen. J Biochem Mol Biol 38:420431. https://doi.org/10.5483/bmbrep.2005.38.4.420

4. Yao Z, Qin D, Chen D, Liu C, Chen W, Liu T, Liu B, Gao L (2019) Development of ISSR-derived SCAR marker and SYBR green I real-time PCR method for detection of teliospores of Tilletia laevis Kühn. Sci Rep 9:17651. https://doi.org/10.1038/s41598-01954163-5

5. Calistru A-E, Jitareanu G (2016) Applications of x-ray CT for examining soil structure: a review. Bull UASVM Ser Agric 73:18435246. https://doi.org/10.15835/buasvmcn-agr

6. Parlak Y (1981) Seed borne pathogens on wheat (particularly smuts) in Turkey. Eppo Bull 11:83-86

7. Liu X, Cheng X, Wang H, Wang K, Qiao K (2015) Effect of fumigation with 1,3-dichloropropene on soil bacterial communities. Chemosphere 139:379-385. https://doi.org/10.1016/j. chemosphere.2015.07.034

8. Jackson CR, Randolph KC, Osborn SL, Tyler HL (2013) Culture dependent and independent analysis of bacterial communities associated with commercial salad leaf vegetables. BMC Microbiol 13: 274. https://doi.org/10.1186/1471-2180-13-274

9. Pascale A, Proietti S, Pantelides IS, Stringlis IA (2020) Modulation of the root microbiome by plant molecules: the basis for targeted disease suppression and plant growth promotion. Front Plant Sci 10:1741. https://doi.org/10.3389/fpls.2019.01741

10. Shimazu M, Maehara N, Sato H (2002) Density dynamics of the entomopathogenic fungus, Beauveria bassiana Vuillemin (Deuteromycotina: Hyphomycetes) introduced into forest soil, and its influence on other soil microorganisms. Appl Entomol Zool 37: 263-269. https://doi.org/10.1303/aez.2002.263

11. Zhang Y, He J, Jia LJ, Yuan TL, Zhang D, Guo Y, Wang Y, Tang WH (2016) Cellular tracking and gene profiling of Fusarium graminearum during maize stalk rot disease development elucidates its strategies in confronting phosphorus limitation in the host apoplast. PLoS Pathog 12:e1005485. https://doi.org/10.1371/ journal.ppat. 1005485

12. Rebbeck J, Malone MA, Short DPG, Kasson MT, O'Neal ES, Davis DD (2013) First report of Verticillium wilt caused by Verticillium nonalfalfae on tree-of-heaven (Ailanthus altissima) in Ohio. Plant Dis 97:999

13. Manjunatha SV, Naik MK, Khan MFR, Goswami RS (2013) Evaluation of bio-control agents for management of dry root rot of chickpea caused by Macrophomina phaseolina. Crop Prot 45: 147-150. https://doi.org/10.1016/j.cropro.2012.09.003

14. Sharma KK, Singh US, Sharma P et al (2015) Seed treatments for sustainable agriculture - a review. J Appl Nat Sci 7:521-539. https://doi.org/10.31018/jans.v7i1.641 
15. Monga D, Sain SK, Nakkeeran S et al (2018) Effectiveness of seed treatment with recommended fungicides on seed, soil borne diseases and productivity of cotton. J Mycol Pl Pathol 48(3):311-323

16. Shakoor MA, Ahmad M, Zia ullah Ghazali H et al (2014) Chemotherapy of Karnal bunt of wheat: a review. Int J Adv Res Biol Sci 1:163-188

17. Workneh F, Allen TW, Nash GH, Narasimhan B, Srinivasan R, Rush CM (2008) Rainfall and temperature distinguish between Karnal bunt positive and negative years in wheat fields in Texas. Phytopathol 98:95-100. https://doi.org/10.1094/PHYTO-98-10095

18. Slininger PJ, Shea-Andersh MA (2005) Proline-based modulation of 2,4-diacetylphloroglucinol and viable cell yields in cultures of Pseudomonas fluorescens wild-type and over-producing strains. Appl Microbiol Biotechnol 68:630-638. https://doi.org/10.1007/ s00253-005-1907-4

19. Dorigan AF, de Carvalho G, Poloni NM et al (2019) Resistance to triazole fungicides in pyricularia species is associated with invasive plants from wheat fields in Brazil. Acta Sci Agron 41:1-10. https:// doi.org/10.4025/actasciagron.v41i1.39332

20. Ribas e Ribas AD, Spolti P, Del Ponte EM et al (2016) Is the emergence of fungal resistance to medical triazoles related to their use in the agroecosystems? A mini review. Braz J Microbiol 47: 793-799. https://doi.org/10.1016/j.bjm.2016.06.006

21. Ecobichon D (1991) Toxic effects of pesticides. In: Gupta PK (ed) (J) Fundamentals of toxicology, pp 185-202

22. Bending GD, Rodríguez-Cruz MS, Lincoln SD (2007) Fungicide impacts on microbial communities in soils with contrasting management histories. Chemosphere 69:82-88. https://doi.org/10.1016/ j.chemosphere.2007.04.042

23. Kalia A, Gosal SK (2011) Effect of pesticide application on soil microorganisms. Arch Agron Soil Sci 57:569-596. https://doi.org/ 10.1080/03650341003787582

24. Newman MM, Hoilett N, Lorenz N, Dick RP, Liles MR, Ramsier C, Kloepper JW (2016) Glyphosate effects on soil rhizosphereassociated bacterial communities. Sci Total Environ 543:155-160. https://doi.org/10.1016/j.scitotenv.2015.11.008

25. Ryan M (1999) Is an enhanced soil biological community, relative to conventional neighbours, a consistent feature of alternative (organic and biodynamic) agricultural systems? Biol Agric Hortic 17: 131-144. https://doi.org/10.1080/01448765.1999.9754832

26. Caporaso JG, Kuczynski J, Stombaugh J et al (2010) QIIME allows analysis of high-throughput community sequencing data intensity normalization improves color calling in SOLiD sequencing. Nat Publ Gr 7:335-336. https://doi.org/10.1038/nmeth0510-335

27. Edgar RC (2013) UPARSE: highly accurate OTU sequences from microbial amplicon reads. Nat Methods 10:996-998. https://doi. org/10.1038/nmeth.2604

28. Wang Q, Garrity GM, Tiedje JM, Cole JR (2007) Naïve Bayesian classifier for rapid assignment of rRNA sequences into the new bacterial taxonomy. Appl Environ Microbiol 73:5261-5267. https://doi.org/10.1128/AEM.00062-07

29. DeSantis TZ, Hugenholtz P, Larsen N et al (2006) Greengenes, a chimera-checked 16S rRNA gene database and workbench compatible with ARB. Appl Environ Microbiol 72:5069-5072. https:// doi.org/10.1128/AEM.03006-05

30. Bokulich NA, Subramanian S, Faith JJ, Gevers D, Gordon JI, Knight R, Mills DA, Caporaso JG (2013) Quality-filtering vastly improves diversity estimates from Illumina amplicon sequencing. Nat Methods 10:57-59. https://doi.org/10.1038/nmeth.2276

31. Schloss PD, Westcott SL, Ryabin T, Hall JR, Hartmann M, Hollister EB, Lesniewski RA, Oakley BB, Parks DH, Robinson CJ, Sahl JW, Stres B, Thallinger GG, van Horn DJ, Weber CF (2009) Introducing mothur: open-source, platform-independent, community-supported software for describing and comparing microbial communities. Appl Environ Microbiol 75:7537-7541. https://doi.org/10.1128/AEM.01541-09

32. Zhang T, Shao MF, Ye L (2012) 454 pyrosequencing reveals bacterial diversity of activated sludge from 14 sewage treatment plants. ISME J 6:1137-1147. https://doi.org/10.1038/ismej.2011.188

33. Hu M, Wang X, Wen X, Xia Y (2012) Microbial community structures in different wastewater treatment plants as revealed by 454 pyrosequencing analysis. Bioresour Technol 117:72-79. https:// doi.org/10.1016/j.biortech.2012.04.061

34. Bruto M, Prigent-Combaret C, Muller D, Moënne-Loccoz Y (2014) Analysis of genes contributing to plant-beneficial functions in plant growth-promoting rhizobacteria and related Proteobacteria. Sci Rep 4:6261. https://doi.org/10.1038/srep06261

35. Spain AM, Krumholz LR, Elshahed MS (2009) Abundance, composition, diversity and novelty of soil Proteobacteria. ISME J 3: 992-1000. https://doi.org/10.1038/ismej.2009.43

36. McLellan SL, Huse SM, Mueller-Spitz SR et al (2010) Diversity and population structure of sewage-derived microorganisms in wastewater treatment plant influent. Environ Microbiol 12:1376 1376. https://doi.org/10.1111/j.1462-2920.2010.02204.x

37. Liu J, Li C, Muhae-ud-din G et al (2020) Development of the droplet digital PCR to detect the teliospores of Tilletia controversa Kühn in the soil with greatly enhanced sensitivity. Front Microbiol 11:4. https://doi.org/10.3389/fmicb.2020.00004

38. Berbee ML (2001) The phylogeny of plant and animal pathogens in the Ascomycota. Physiol Mol Plant Pathol 59:165-187. https://doi. org/10.1006/pmpp.2001.0355

39. Hamady M, Lozupone C, Knight R (2010) Fast UniFrac: facilitating high-throughput phylogenetic analyses of microbial communities including analysis of pyrosequencing and PhyloChip data. ISME J 4:17-27. https://doi.org/10.1038/ismej.2009.97

40. Palaniyandi SA (2013) Effects of actinobacteria on plant disease suppression and growth promotion. Appl Microbiol Biotechnol 97: 9621-9636. https://doi.org/10.1007/s00253-013-5206-1

41. Singh S (2014) A review on possible elicitor molecules of cyanobacteria: their role in improving plant growth and providing tolerance against biotic or abiotic stress 117:1221-1244. https:// doi.org/10.1111/jam.12612

42. Oehmen A, Saunders AM, Vives MT, Yuan Z, Keller J (2006) Competition between polyphosphate and glycogen accumulating organisms in enhanced biological phosphorus removal systems with acetate and propionate as carbon sources. J Biotechnol 123: 22-32. https://doi.org/10.1016/j.jbiotec.2005.10.009

43. Gans J, Wolinsky M, Dunbar J (2005) Computational improvements reveal great bacterial diversity and high toxicity in soil. Sci 309:1387-1390. https://doi.org/10.1126/science.1112665

44. Philippot L, Raaijmakers JM, Lemanceau P, Van Der Putten WH (2013) Going back to the roots: the microbial ecology of the rhizosphere. Nat Rev Microbiol 11:789-799. https://doi.org/10.1038/ nrmicro3109

45. Keane BJ, Ineson P, Vallack HW, Blei E, Bentley M, Howarth S, McNamara NP, Rowe RL, Williams M, Toet S (2018) Greenhouse gas emissions from the energy crop oilseed rape (Brassica napus); the role of photosynthetically active radiation in diurnal $\mathrm{N} 2 \mathrm{O}$ flux variation. GCB Bioenergy 10:306-319. https://doi.org/10.1111/ gcbb. 12491

46. Zhu X, Wang Y, Su Z, Lv L, Zhang Z (2018) Silencing of the wheat protein phosphatase $2 \mathrm{~A}$ catalytic subunit TaPP2AC enhances host resistance to the necrotrophic pathogen rhizoctonia cerealis. Front Plant Sci 9:1437. https://doi.org/10.3389/fpls.2018.01437

47. Lin W, Liu W, Xue Q (2017) Spring maize yield, soil water use and water use efficiency under plastic film and straw mulches in the Loess Plateau. Sci Rep 6:38995. https://doi.org/10.1038/srep42455

48. Muñoz K, Buchmann C, Meyer M, Schmidt-Heydt M, Steinmetz Z, Diehl D, Thiele-Bruhn S, Schaumann GE (2017) Physicochemical and microbial soil quality indicators as affected by the agricultural 
management system in strawberry cultivation using straw or black polyethylene mulching. Appl Soil Ecol 113:36-44. https://doi.org/ 10.1016/j.apsoil.2017.01.014

49. Zhang M, Xu JH, Liu G, Yao XF, Li PF, Yang XP (2015) Characterization of the watermelon seedling infection process by Fusarium oxysporum $f$. sp. niveum. Plant Pathol 64:1076-1084. https://doi.org/10.1111/ppa.12355

50. Agler MT, Ruhe J, Kroll S, Morhenn C, Kim ST, Weigel D, Kemen EM (2016) Microbial hub taxa link host and abiotic factors to plant microbiome variation. PLoS Biol 14:e1002352. https://doi.org/10. 1371/journal.pbio.1002352

51. Berendsen RL, Pieterse CMJ, Bakker PAHM (2012) The rhizosphere microbiome and plant health. Trends Plant Sci 17:478486. https://doi.org/10.1016/j.tplants.2012.04.001
52. Bulgarelli D, Rott M, Schlaeppi K, ver Loren van Themaat E, Ahmadinejad N, Assenza F, Rauf P, Huettel B, Reinhardt R, Schmelzer E, Peplies J, Gloeckner FO, Amann R, Eickhorst T, Schulze-Lefert P (2012) Revealing structure and assembly cues for Arabidopsis root-inhabiting bacterial microbiota. Nature 488: 91-95. https://doi.org/10.1038/nature11336

53. Muhae-ud-Din G, Moosa A, Ghummen UF et al (2018) Host status of commonly planted ornamentals to Meloidogyne incognita and management through endophytic bacteria. Pak J Zool 50:13931402. https://doi.org/10.17582/journal.pjz/2018.50.4.1393.1402

54. Xu J, Liu S, Song S, Guo H, Tang J, Yong JWH, Ma Y, Chen X (2018) Arbuscular mycorrhizal fungi influence decomposition and the associated soil microbial community under different soil phosphorus availability. Soil Biol Biochem 120:181-190. https://doi. org/10.1016/j.soilbio.2018.02.010 